\title{
MODULAR PROSTHESES
}

\author{
A possible Extension of the Traditional Physical Therapy \\ Role in the management of Amputee Patients.
}

JOAN M. WALKER, B.P.T., N.Z.R.P., Dip. T.P., School of Medical Rehabilitation, 800 Sherbrook Street, Winnipeg, 2, Canada.

Physical therapy has a vital role to play in the rehabilitation of amputee patients. An amputee patient normally has a lengthy period of contact with physical therapy while waiting for fitting of the final or definitive limb. This fitting is normally delayed until maximum stump shrinkage has been achieved. What can the therapist do to assist in reducing this period? What can be done to reduce the tedious repetitive exercise programme necessary during this period to improve and then maintain an adequate level of fitness, particularly in relation to the stump musculature? Can the modern therapist in small centres away from close contact with a prosthetist enlarge the traditional physical therapy role to help provide a better service for amputee patients?

At the Manitoba Rehabilitation Hospital all amputee patients receive daily, and often twice daily, treatment on the Jobst Peripheral Compression Unit in addition to the traditional programme of stump bandaging. Patients also receive treatment on this Unit prior to casting for a socket by the prosthetist. There is a need for a comprehensive clinical study to determine exactly the effect the use of the Jobst unit has on stump shrinkage over a period of time and in different age groups.

Traditional exercise programmes, particularly for the geriatric amputee patients are best replaced with programmes involving normal activities using a prosthesis, and exercising the stump muscles in a functional manner. Immediate post-operative plaster of paris fitting allows early re-education of gait and practice of functional activities; however, this technique has not always proved successful. The use of modular prostheses, as described in the following two articles, allows the patient to commence training with a prosthesis from the time of removal of sutures and can thus provide a means of reducing the need for lengthy exercise periods in the traditional form.

Modularization can provide for an extension of the traditional therapy role in the management of amputee patients as well as reducing the overall length of the rehabilitation period. This extension of role could prove most effective for therapists working in smaller centres where resident prosthetic services are absent. A therapist trained in the use of modular prostheses can negate the need for a prosthetist to travel around the country seeing patients and can enable the prosthetist to devote his time to construction of prostheses. Alternatively, an amputee patient in a small centre need not travel to the larger centres for fitting of a prosthesis. Physical therapists have the necessary knowledge and skill and, with further training, could assume the task of taking the negative plaster of paris mould from which the prosthetist will make the definitive socket. This would mean that only the negative mould and the final socket travels. In the outlying centres the prefabricated components could be kept in the physical therapy department and be assembled by the physical therapist who is also capable, following training, of making alignment changes as required.

This writer is not proposing to "take-over" normal duties of prosthetists, but is suggesting that modularization of prostheses may enable a greater number of amputee patients to be provided with improved service at lower cost to either the patient or the social service involved.
The following arricles on Modular Prostheses were produced especially for publication in the South African Journal Physiotherapy by kind arrangement of Miss Joan Walker, B.P.T., N.Z.P.P., Dip. T.P., formerly lecturer at the Sub-Department of Physiotherapy, University of Witwatersrand.

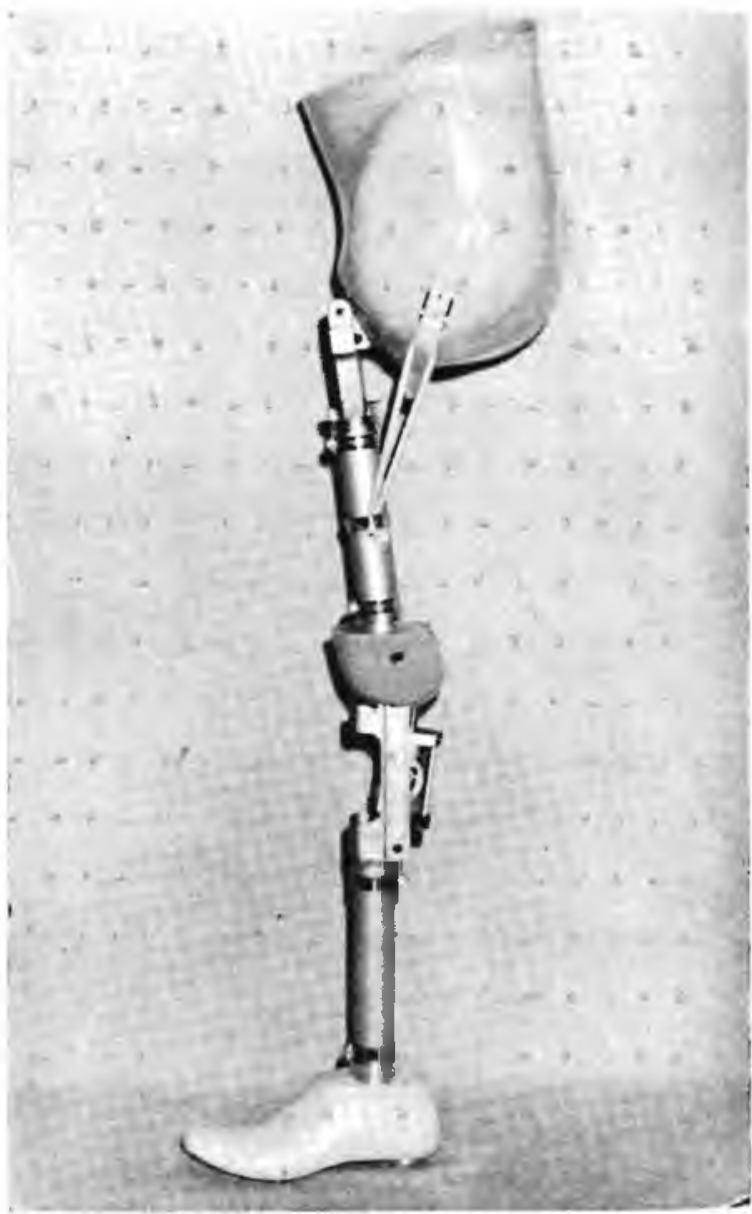

A modular Hip Disarticulation Prosthesis of the Winnipeg type. 